\title{
CORE AND PERIPHERY OF INFORMATION SOCIETY: SIGNIFICANCE OF GEOSPATIAL TECHNOLOGIES
}

\author{
Piotr A. Werner, Tomasz Opach \\ Faculty of Geography and Regional Studies, University of Warsaw, Warsaw, Poland \\ Manuscript received: October 10, 2011 \\ Revised version: April 11, 2013
}

\begin{abstract}
Werner P.A., Opach T., 2013. Core and periphery of information society: Significance of geospatial technologies. Quaestiones Geographicae 32(2), Bogucki Wydawnictwo Naukowe, Poznań, pp. 39-49. 1 table, 12 figs. DOI 10.2478/quageo-2013-0012, ISSN 0137-477X.
\end{abstract}

ABSTRACT. The paper attempts to identify important factors significant for global information society development and to determine the significance of geospatial (geo-information) technologies. The starting point is international measures of the development level of information \& communication technologies (ICT) and information society (IS). The relevance of the particular factors was defined using the general segmentation of the milieu, taking into account social, technological, economic, environmental, political, legal and ethical factors and also estimating the global spatial dimension of ICT and IS development. The diagnosis serves as the context of considerations concerning the contribution of geographers and cartographers to IS.

KEY wORDS: information society, GIS, ICT, geospatial technologies, geo-information

Piotr A. Werner, Laboratory of Computer Education \& GIS, Faculty of Geography and Regional Studies, University of Warsaw, ul. Krakowskie Przedmieście 30, 00-950 Warsaw, Poland; e-mail: peter@uw.edu.pl

Tomasz Opach, Chair of Cartography, Faculty of Geography and Regional Studies, University of Warsaw, ul. Krakowskie Przedmieście 30, 00-950 Warsaw, Poland; e-mail: topach@uw.edu.pl

\section{Introduction}

In 1997, physicist Professor Tomasz Hofmokl (1936-2000), director of the first Internet providing firm in Poland, NASK, defined information society as one in which information has become a production resource giving it new competitive advantages over the milieu while ensuring a growing level of social adaptability to the rapidly changing milieu for both, the society at large and individuals (Hofmokl 1997).

Recently, information and communication technologies (computers and telecommunication) are perceived as the main cause of changes in the milieu. Today, sectors that play main roles in the economy are quite different than in the past - mainly multimedia and mass media. All those sectors have gone through a violent transformation during last decades (often defined as a digital revolution) and have become electronic media using digital information.

Within the framework of social sciences, adaptability is defined as a basic social competence, an ability to adjust to different social situations. The avalanche of technological novelties announced by media week after week, month after month, year after year, is less and less noticed by people, in spite of solutions and devices fundamentally 
changing the functioning, organisation and order of society to which people are accustomed. The revolution disappears from people's horizon and transforms into an evolution. Social adaptability makes people insensitive and they simply use new 'black box' ICT technologies looking for an optimal space for their own development.

The title of this paper refers to the well-known core-periphery model (Friedmann 1966). But its aim is not to verify this model in the IS context, but rather use it as a metaphor that can help in a deeper and proper understanding of ICT phenomena and processes, especially concerning the place and significance of geospatial technologies.

\section{Dimensions of information society}

The spatial distribution of the global IS core-periphery can be estimated using international measures of information society, i.e. the ICT Development Index (Fig. 1).

At a glance one can observe the high correlation of IS development with GDP per capita (correlation coefficient $r=+0.81$ ) and with urbanisation (correlation coefficient $r=+0.71$, see Fig. 2). Scholars agree that "cities are giant pools of information" (Domański 1988).

The core-periphery model is literally and metaphorically a starting point for considerations concerning IS. Literally, because the model can be applied directly, even based on the above superficial analysis. Metaphorically, because we can use Tomasz Hofmokl's definition of IS, the one cited above and involving the category of social adaptation. It is accurate to consider the IS core-periphery system in its various aspects, or dimensions.

The cores of IS are urbanised, rich areas of the world. Rural areas are usually perceived as the periphery. This is the spatial aspect (dimension) of IS defining the extent of ICT effects. Another one, derived from the above definition, is the scale of social, institutional and individual participation in information society, which can be described as the opposing poles of this scale. It is not obvious that these poles are the core of IS. According to the first World Summit on Informa-

\section{Development of Information and Communication Technologies}

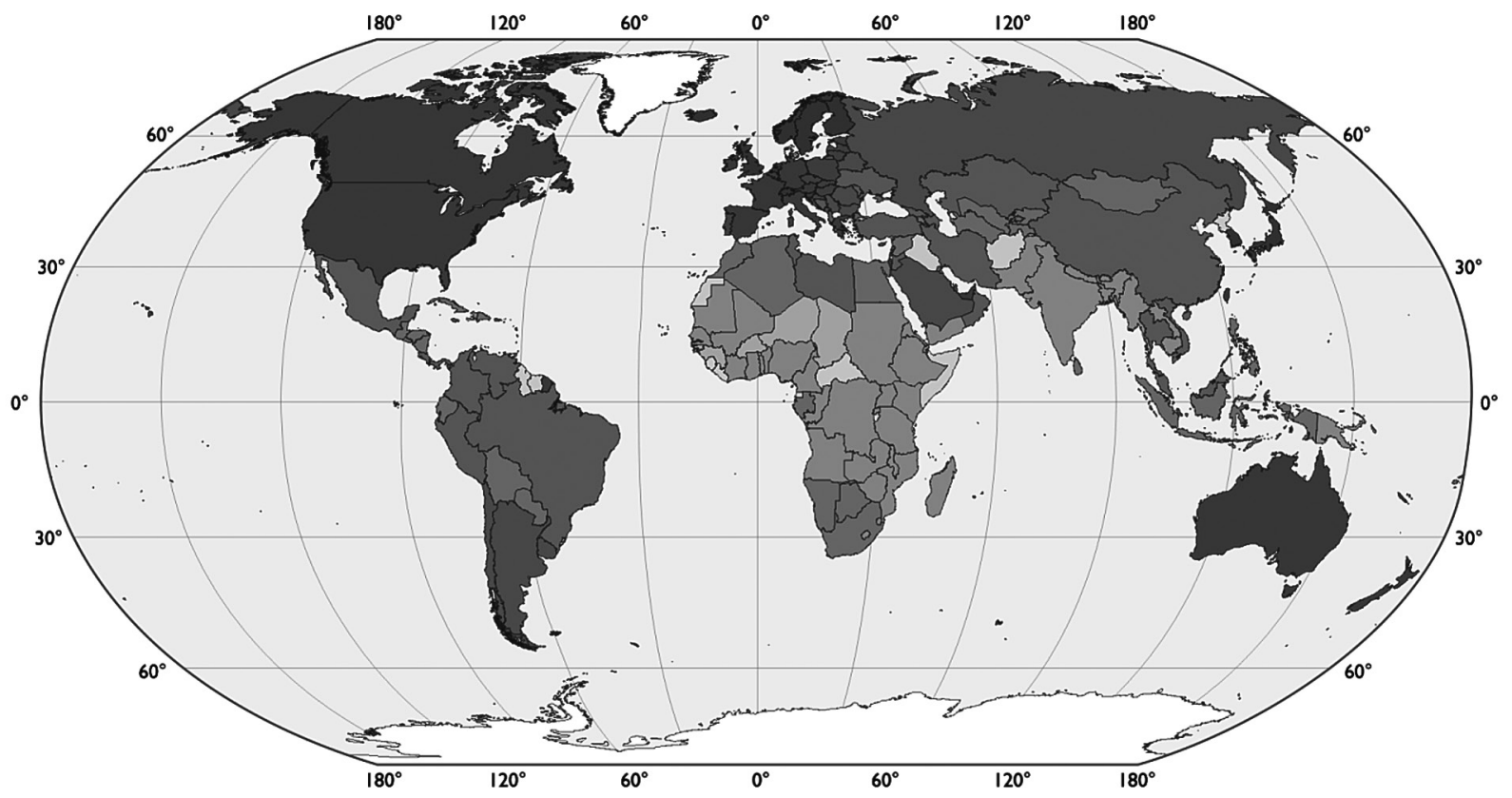

Information and Communication Technologies Development Index in 2008:

Fig. 1. Spatial distribution of ICT Development Index 2008. 

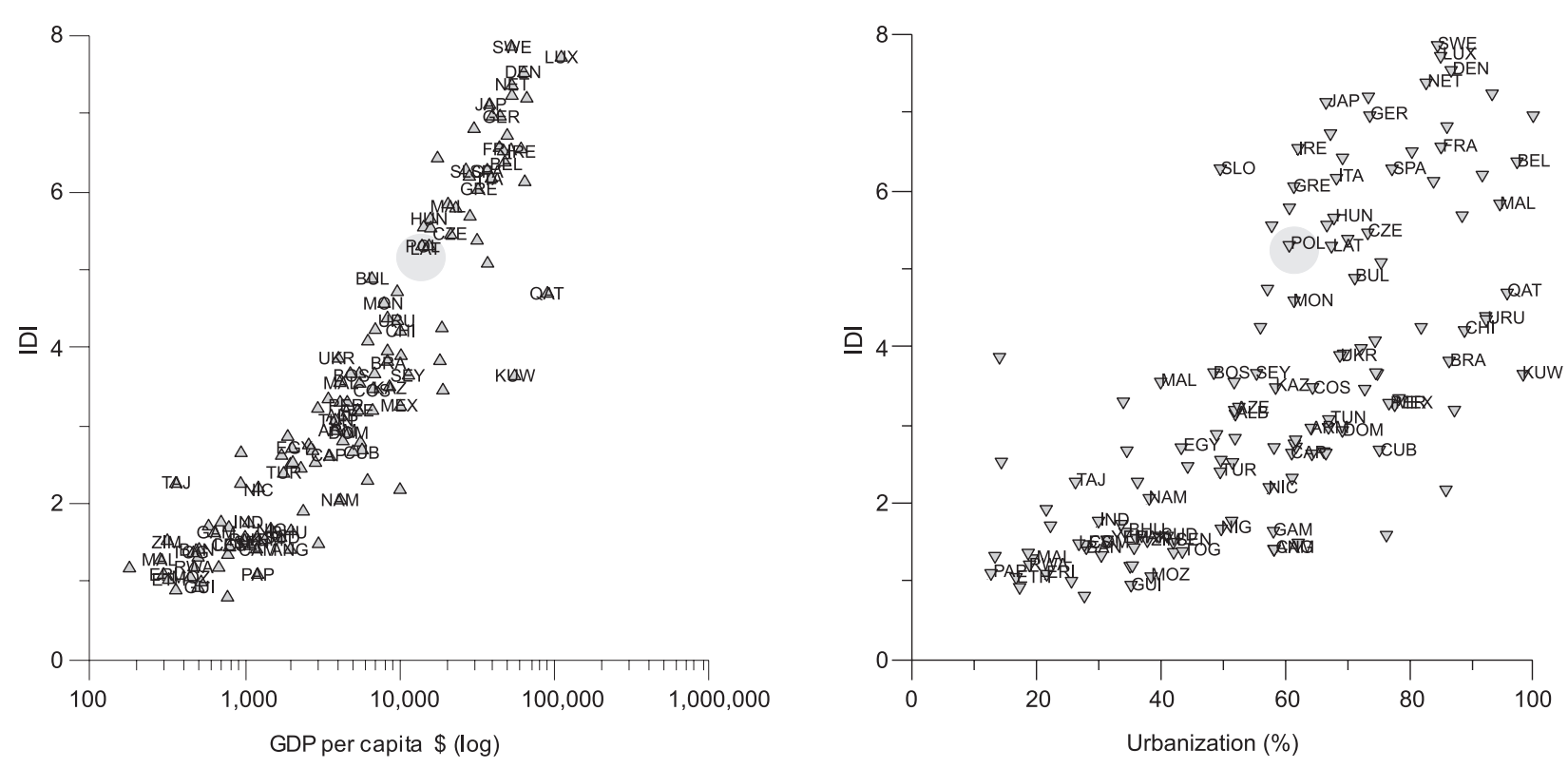

Fig. 2. ICT Development Index vs. urbanisation and GDP per capita by country. Source: ITU (2011), UN.

tion Society in Geneva (2003), the importance of the various aspects of IS development concerning participation can be estimated on the basis of the Action Lines the summit defined (see Fig. 3).

The recent (May 2011) WSIS statistics collected for Geneva show quite different participation of stakeholders than the WSIS Tunis (2006) data (Fig. 4). The focus of interest moved to greater participation of civil society with a significant share of non-governmental organisations, in spite of the initiatives of governmental and international organisations at the beginning.

The construction of the ICT Information Development Index (ITU 2011) reveals others dimensions (scales) of the core-periphery metaphor. The ICT IDI measure is a weighted average of complex sub-indices describing a set of significant factors treated as basic conditions of information society development. Those are access, use, and skills sub-indices. They describe ICT readiness, the intensity, and the impact of (and on) IS. The sub-indices contribute $40 \%, 40 \%$ and $20 \%$, respectively, to the ICT IDI.

The global average ICT IDI (2008) equals 3.58, but the order of the sub-indices is different if we consider them separately (Fig. 5). Taking their empirical values, the order is the following: skills, access, and use. The skills sub-index covers liter- acy as well as the gross secondary and tertiary school enrolment ratio (ITU 2010).

\section{Factors determining IS development}

Four Cs: carriers, contents, commons, and communities, are the pillars of today's IS (d'Haenes et al. 2000).

\subsection{Carriers}

A prerequisite and necessary condition of IS development is access to resources using carriers.

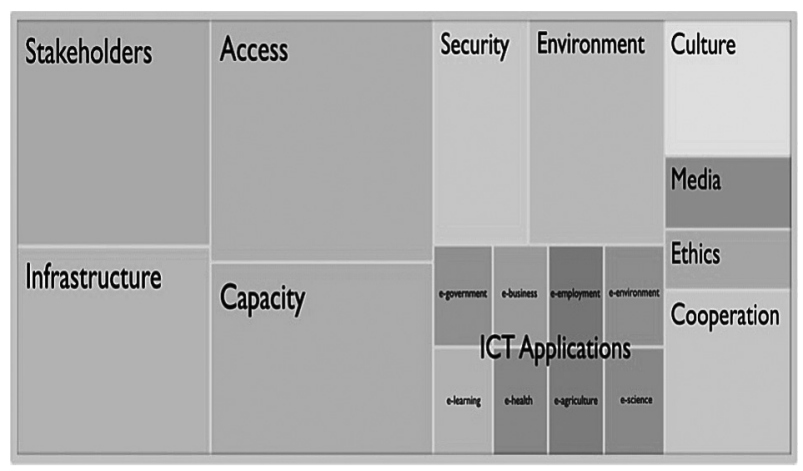

Fig. 3. Action Lines of the 2011 World Summit on Information Society (WSIS).

Source: http:/ /www.itu.int/wsis/index.html). 


\section{5}

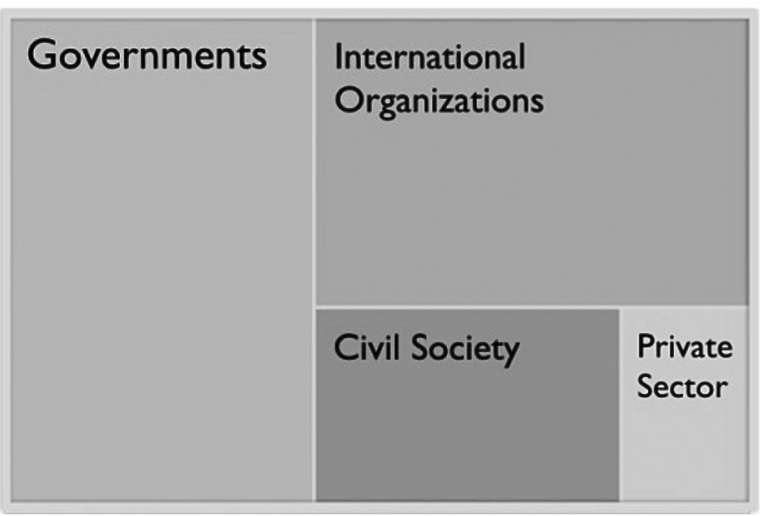

\section{1}

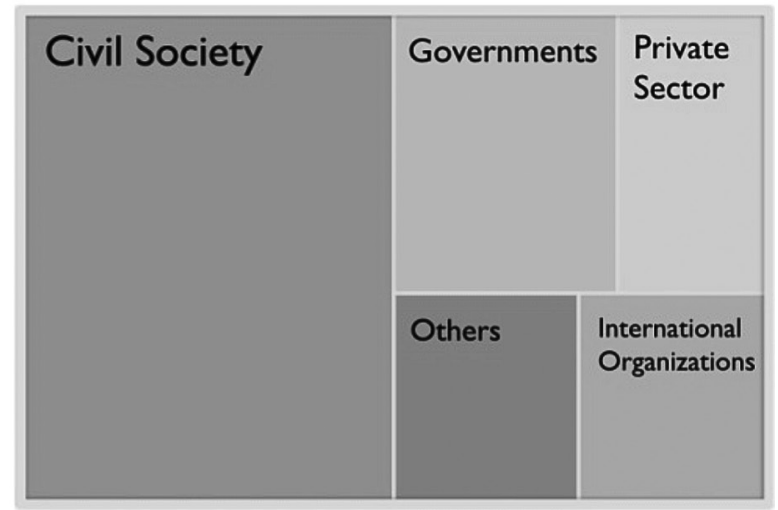

Fig. 4. Participation in IS development according to the WSIS Action Lines (WSIS 2005, 2011).

nominal values - weighted

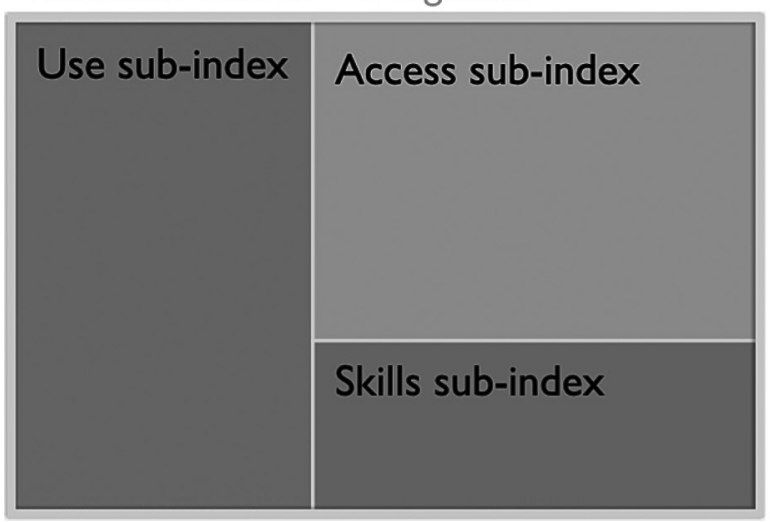

empirical values - averages

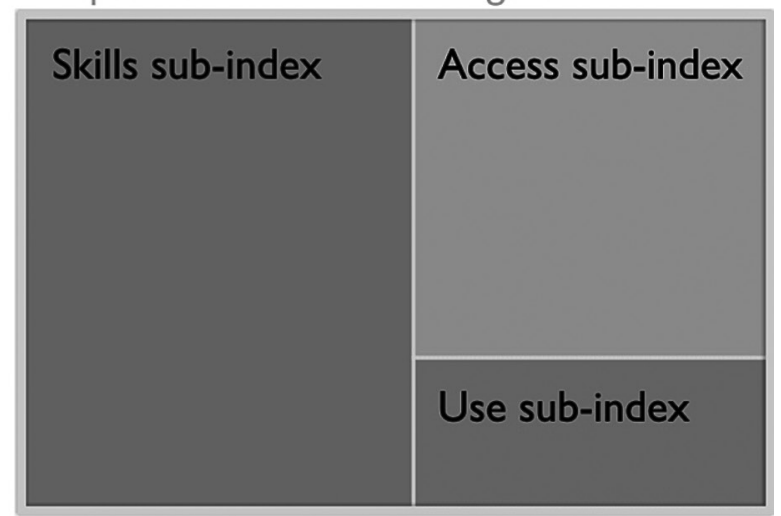

Fig. 5. Nominal proportions and empirical-value proportions of the ICT IDI sub-indices.

Those used currently are broadband networks and dedicated devices (computers, smartphones, GPS devices, ATMs). The technological dimension of the IS core-periphery is defined by the IDI access sub-index. It embraces fixed telephony, mobile telephony, international Internet bandwidth, households with computers, and households with the Internet (Fig. 6).

Access to resources is also related to individual skills of users and how they use the functionality of the ICT carriers. It concerns individuals, households and firms. The milieu of youth growth, early contact with ICT, education, and ability to work in hi-tech firms on the one hand as well as individual psychology and imagination on the other, shape an individual's skills and ability to use ICT. Full use of possible devices and technologies needs knowledge and a defined level of technical skills. It is related with the level of education and the technical culture of society. There are digitally divided individuals on opposite poles (Peterson 2007). The digital divide is given much atten- tion. "The term 'digital divide' refers to the gap between individuals, households, businesses and geographic areas at different socio-economic levels with regard to both their opportunities to access information and communication technologies (ICTs) and to their use of the Internet for a wide variety of activities. The digital divide reflects

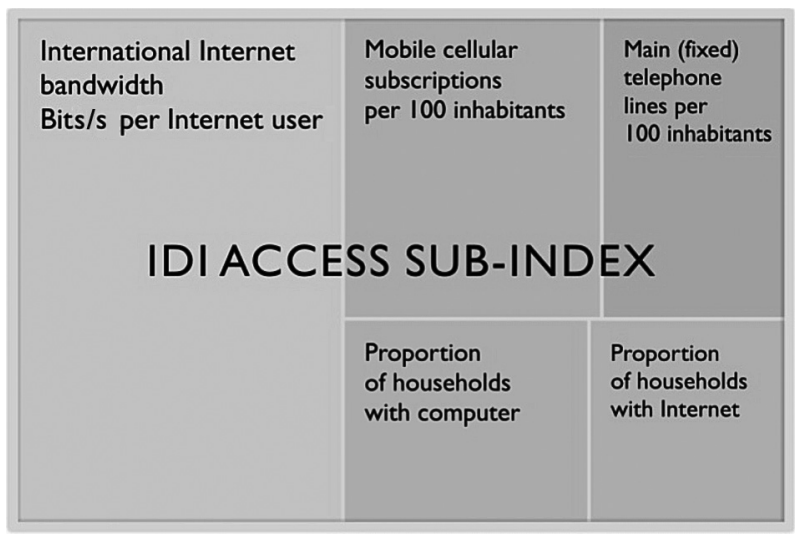

Fig. 6. Empirical values of the proportion of indicators of the IDI access sub-index. Source: ITU 2011. 
various differences among and within countries" (OECD 2001). The ITU analysis treats the ICT IDI as a measure of a digital divide. It is an opposite to IS development.

An analysis of the empirical values of components of the access sub-index for countries of the world proves that the engines of the new technologies are broadband Internet and cellular telephony (Fig. 6). It does not matter much if households use computers, even connected to the Internet, because Net access is usually gained through mobile devices (smartphones, netbooks, tablets, GPS devices) as part of the wi-fi broadband network. A little bit more significant are also wired networks, especially those equipped with fibre optic cables.

This is the mobile IS dimension. Its opposite poles are mobile and wired devices. An example of the latter is LBS (Location Based Service); the classic wired network services are mass accommodation booking transactions, or bank or firm electronic financial payments. Obviously, this indicator also describes the level of the technological advancement of IS.

\subsection{Contents}

The main element attracting Internet users is digital resources (contents), both of information and services (Table 1). They can be described as attractors in this context.

Known and accepted in the digital economy are both, free or public files (tickets, payments, timetables) and copyrighted files (scientific, multimedia, cartographic and software). There are also network access services providing access to digital resources. Cultural changes involve the intensity and new forms of collecting and sharing digital information. There are three interdependent elements: creators of information, network operators and programmers providing access to information, and Internet users. The value and accessibility of information resources are the function of usability (also software), differentiation of information, internationalisation (multi-language information), low price of accessibility, and openness - application of publicly known and used standards, including data and meta-data formats.

It should be stressed that easy access attracts users to resources and services, i.e. easy interfaces of devices and an impressive and effective form of information transfer (see Figs 7 and 8).

When considering IS, one can touch upon a variety of ICT applications: e-government, e-business, e-learning, e-health, e-employment, e-environment, e-agriculture, or e-science (ITU 2011), but the top sector of its own is multimedia, not preceded by the letter $e-$, assuming that they are the cutting edge of the " 3 rd industrial revolution" (Warnecke 1993).

\subsection{Commons and communities}

Problems of common access to the Internet, its services and resources are (probably) currently the flash point of disagreement among users, operators, providers, creators, publishers, as well as national and international organisations. The Internet has its roots in a (hobbyist) hacker's culture (in the forgotten meaning of this word). But the evolution of the attitudes of Internet users, its dynamically changing content and its bandwidth development penetrating into all domains of society create quite a new situation.

The Net creates virtual communities across territorial, ethnic and cultural borders. Quite a new social phenomenon (and one not well-studied yet) is relations with the real, geographical groups and societies. Sociologists, journalists and media specialists have identified and named these phenomena as the next $(\mathrm{Y})$ generation, i.e. the Web 2.0 one. There are numerous examples of social networking services based on Web sites with users from all over the world. Of significance are both the country of location of the supporting technical infrastructure as well as the origin, residence, social and demographic characteristics of the users. Usually there are three groups: initiators, moderators,

Table 1. Internet resources.

\begin{tabular}{|l|l|l|}
\hline \multicolumn{1}{|c|}{ Internet resources } & \multicolumn{1}{c|}{ Copyrighted } & \multicolumn{1}{c|}{ Free/public } \\
\hline information & e.g. multimedia, software & e.g. timetables, law, taxes \\
\hline services & e.g. blogs, comments & e.g. Internet traders, tickets, financial payments \\
\hline
\end{tabular}




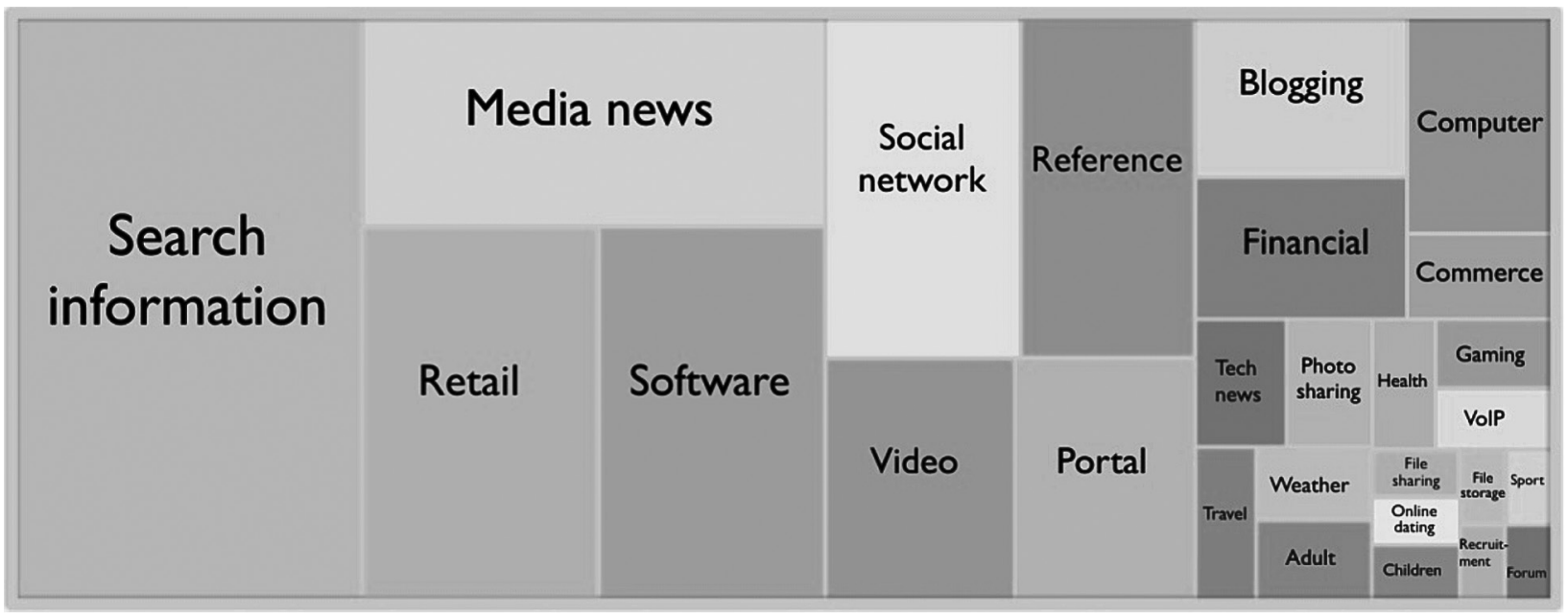

Fig. 7. Typical European Internet user actions.

Source: http://news.bbc.co.uk/2/hi/technology/8562801.stm (accessed 23 March 2011).

\begin{tabular}{|c|c|c|c|c|c|c|c|}
\hline \multirow{2}{*}{\multicolumn{2}{|c|}{ e-mail }} & \multirow{2}{*}{$\begin{array}{l}\text { Internet } \\
\text { forum }\end{array}$} & \multirow{2}{*}{\multicolumn{2}{|c|}{$\begin{array}{l}\text { Online } \\
\text { banking }\end{array}$}} & \multirow{2}{*}{$\begin{array}{l}\text { RTV } \\
\text { online }\end{array}$} & Journals & \multirow[t]{2}{*}{ Travels } \\
\hline & & & & & & Books & \\
\hline \multirow{2}{*}{\multicolumn{2}{|c|}{ Info }} & \multirow{3}{*}{ Health } & \multicolumn{2}{|l|}{ Music } & \multirow{3}{*}{ VolP } & Software & \multirow[t]{2}{*}{ Work } \\
\hline & & & \multicolumn{2}{|c|}{ Multimedia } & & & \\
\hline Services & Products & & Films & Games & & & \\
\hline
\end{tabular}

Fig. 8. Typical actions of Polish Internet users. Source: Central Statistical Bureau, 2011.

and active users. A limitation to dissemination is the language barrier. English-speaking nations and groups are privileged (Goban-Klas 2006).

The Net commons and communities are related and create a specific milieu. According to Levinson (1997), the development of information and communication media is often related to technologies and inventions for which people define their own use quite different from that of their original creators. People control the evolution of ICT with unintended consequences.

\section{The role of geospatial technologies}

Geographers also observe and are convinced that geospatial technologies affect the various sectors of the economy, culture and education, and are used in all their dimensions: individual, social and institutional. Geo-portals providing geographical and thematic information, LBS, GPS, optimisation of car fleets, or Internet maps are examples of the spatial content of the Internet and geo-technologies. Geospatial technologies are perceived not only as computing tools, but also as a scientific, economic and management sector. These services are part of the market for individuals, firms, municipalities and governments. They have become an important element 
of today's knowledge-based economy (knowledge society). At first Geographic Information Systems were perceived as special software, later they have started to be treated as a whole geospatial sector. This evolution is stimulated by the earth, space and computer sciences, while on the other hand it is an effect of the demand generated by the economy (including individuals).

Geospatial technologies are sometimes only components of wider systems, but they are the core of innovative services or products in numerous applications. These product (material) innovations are, for example, GPS devices. Immaterial (process) innovations in geospatial technologies are, for example, shared digital web maps; there are also organisational innovations, like the management of a cadastral system, and marketing ones, like Google's version of the virtual globe (classification according to the OECD Oslo Manual).

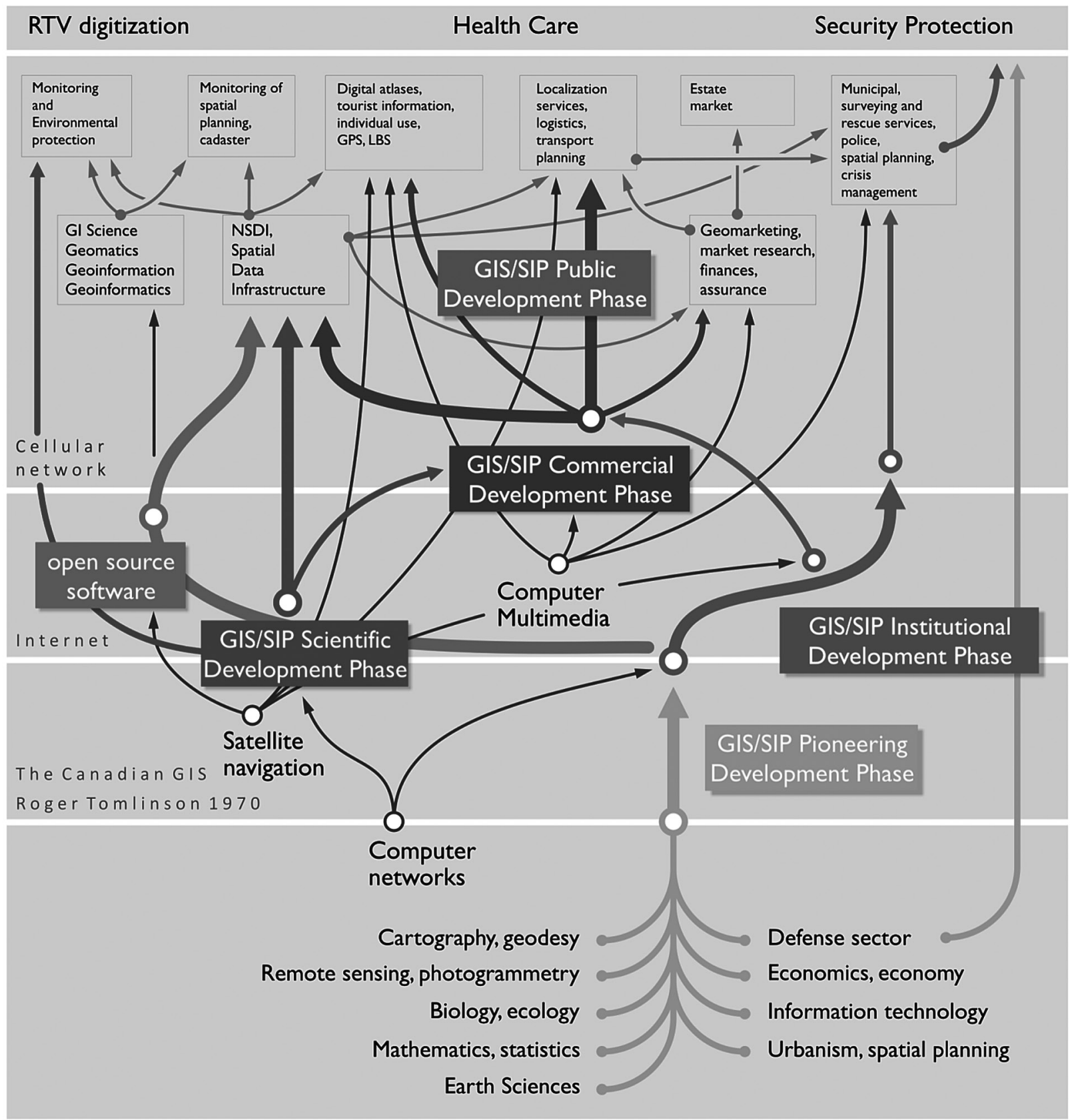

Fig. 9. Geospatial technologies projection (own study; visualisation inspired by Steinitz 1993). 
There are milestones in the development of geospatial technologies, traced from the beginning. The history of GIS is well documented and numerous papers have aimed to define the directions of its future development. The present authors' projection has taken the graphical form shown in Fig. 9.

Reliable and objective sources of information on progress of geo-technologies have been derived from an analysis of thematic sessions of the International Cartographic Congress $\left(24^{\text {th }}\right.$ ICC in Santiago, Chile, Nov. 2009) and the International Geographic Union Congress (IGC in Tunis, May 2008).

There were over 700 academics and practitioners, including representatives of enterprises, participating in 30 thematic sessions of the ICC in Santiago. The dominating subjects were geospatial technologies and their application. It is obvious that (taking into account the number of the papers presented) geo-technologies become the main axis of research in cartography and remote sensing (Fig. 10). We believe and confirm this conclusion, being witnesses of those events.

The thematic range of the IGC sessions in Tunis was similarly analysed and presented (Fig. 11), keeping the original French titles of the sessions and distinguishing those related to the development and use of new geo-technologies (although the authors reserve themselves the right to subjective judgment and leave the reader the freedom of interpretation). The analysis was based on historical information from the Internet-archived IGC documents (among others the Wayback Machine).

Undoubtedly there was a wide spectrum of problems presented in the thematic sessions during the IGC in Tunis. It seems that little change had taken place since the IGU Congress in Washington in 1992. Then one of the comments reflecting a participant's impressions was the following: "The papers submitted to the congress properly encompassed the breadth of the discipline, with the eclecticism to be expected of a conclave of geographers [the authors' note: and cartographers .... . Series of plenary sessions, symposia and sponsored sessions, designed to 'cut across the usual sub-division of the discipline - and between the discipline and the world around it - to address some of the most important social, economic and environmental issues of our time.' (...) The plenary sessions were ostensibly to bring together professional geographers and leading policymakers 'to explore global and national issues that need to be illuminated by geographic insights'. Laudable though these goals seemed, this special programme revealed that trained and professional geographers were minority contributors on the major contemporary social, economic and environmental issues facing the world and the Americas. In virtually every session non-geographers dominated. Even more strikingly (...)
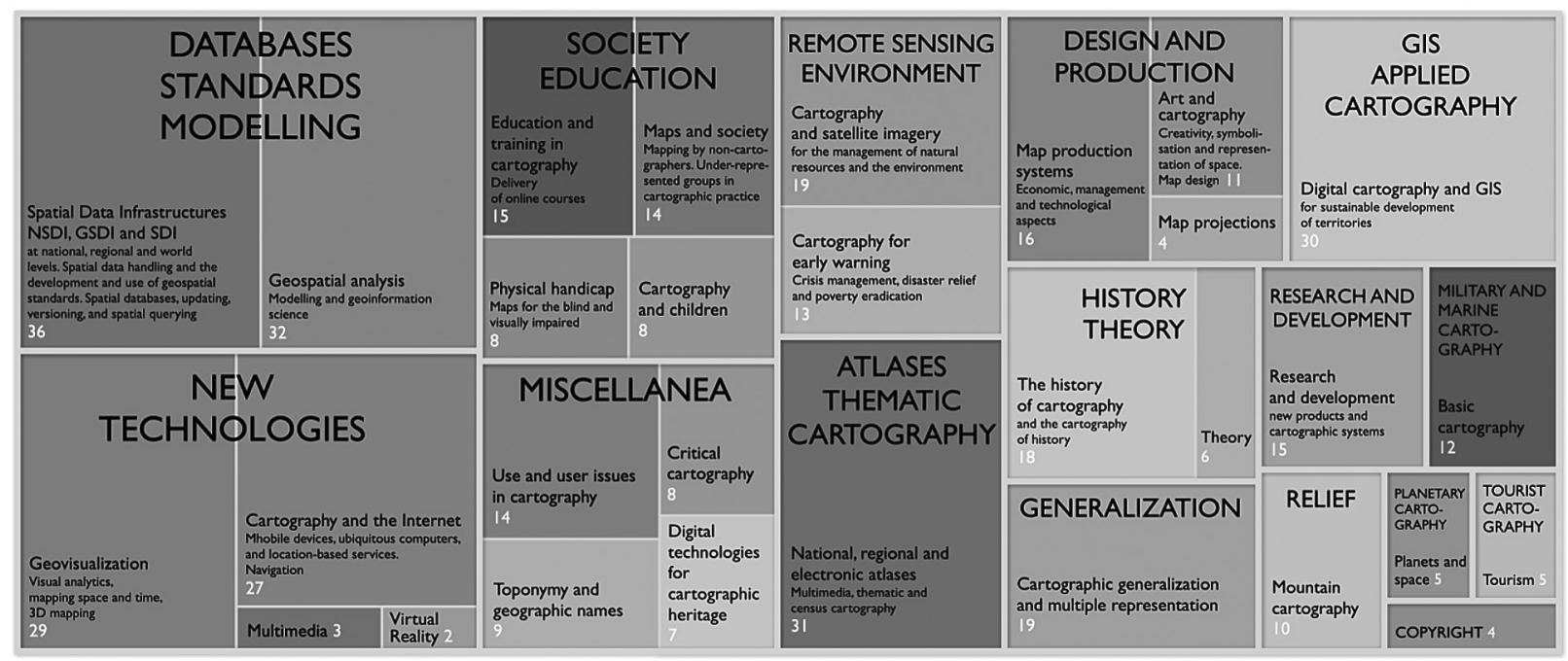

Fig. 10. Thematic sessions of the 25th ICC in Santiago de Chile (2011). 30 sessions were grouped into 16 categories (own study based on the conference programme). 


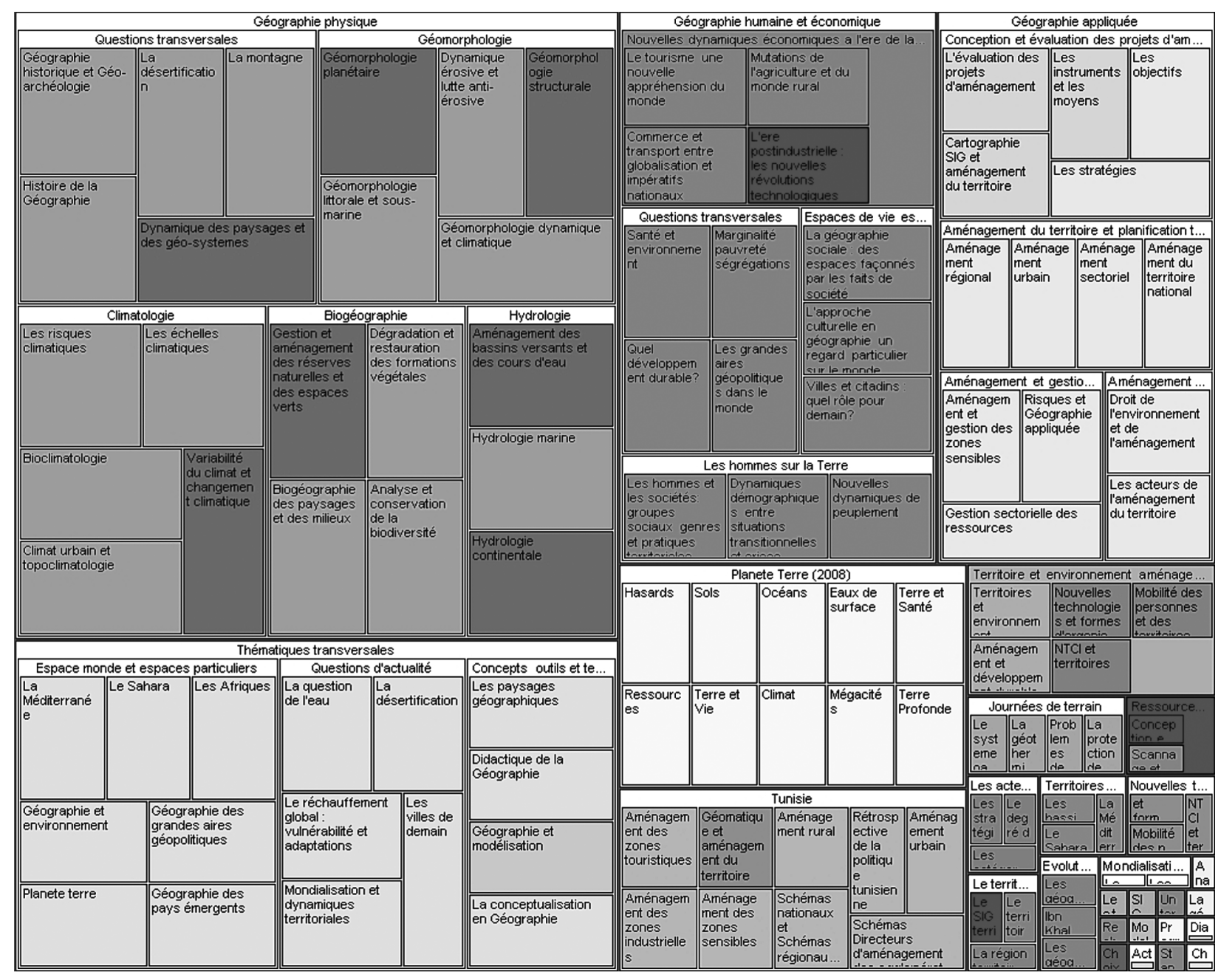

Fig. 11. Thematic sessions of the IGC in Tunis (French titles, 2008, own study based on historical WEB and IGU documents).
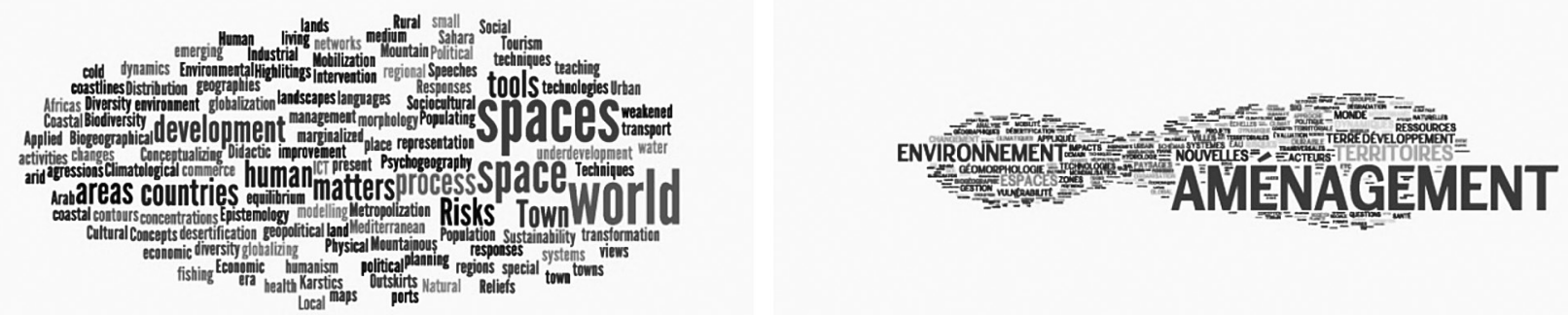

Fig. 12. Surprising difference between the tags clouds of keywords of thematic session papers in English and French at the IGC in Tunis, 2008 (own study based on the conference programme)

both geographical and non-geographical, were overwhelming." (Dickenson 1993).

At this point it is worth mentioning another observation. Looking for an optimal graphic expression illustrating the structure of the thematic sessions of the congress in Tunis and in an attempt to assess the presence and impact of geospatial technologies, we used the so-called tags cloud. There is a clear difference between the visualisations of keywords of the thematic sessions of papers in English and in French (Fig. 12). It strengthened our belief concerning the diversification of the English and French approaches to geography.

\section{Conclusions}

The role of geospatial technologies in geography, their presence and significance in IS, and the 
level of use (both by individuals and society) are difficult to assess. In the authors' opinion, one can find an analogous situation in the history of geographical sciences. There are similarities and differences when we compare the recent times with the 'quantitative revolution' in geography (the late 1970s). Current spatial studies use geo-information technologies extensively. The mathematical and statistical methods introduced into geography in the 20th century were borrowed from other branches of sciences. But it was not only ordinary copying. According to Longley et al. (2001), these methods were adapted, creatively developed and sometimes even re-exported to other sciences, or applied in the economy. They were the base to generalisations and applications of geographical studies. The roots of geospatial technologies are (at least partly) outside geography, although cartographic methods are widely employed here. Geographic Information Systems derive from both, other branches of science and the practice of the economy. The process of the development of geospatial technologies continues in the context of complex relations among science, economy and society. The origin of main impulses of geospatial technologies are from outside geography and even outside science; they are a result of real economic applications.

Thomas Kuhn (1963) described the scientific paradigm as "universally recognised scientific achievements that, for a time, provide model problems and solutions for a community of researchers" and at least as a pattern of scientific practice extended onto applications and technical solutions and methods. One can see even the seeds of regularities and theories derived from geographical research with the use of geospatial technologies. They result from the use of a huge amount of spatial data at a scale never practised before. They concern the processes of globalisation, human-environment interactions, monitoring of changes in land cover, or natural hazards - floods, earthquakes and landslides. There has appeared a new kind of geographical studies dealing (among other things) with methods of geo-visualisations and dynamic presentations of geospatial processes. Scientific achievements employing geospatial technologies are nowadays accepted by geographers and treated as foundations of a further practice of 'normal science'.
They are original achievements of the researcher community and still leave a host of problems to solve. They are the basis of the emerging pattern of current scientific practice. All those threads create a model from which there emerges a new consistent tradition of the science of geography. We can call it a geo-information paradigm of geography.

What are the implications of this new paradigm of geography originating from the application of geospatial technologies? The geo-information paradigm undoubtedly strengthens the integration of geography as a science. Geospatial technologies are surely common tools and the common plane of both, physical and socio-economic geography (interdisciplinary studies). The main issues and research problems are retained: location, spatial order and spatial division, relations between the environment and human activities; moreover, also retained are open research fields for both, physical and socio-economic geography. This understanding constitutes a logical continuation of the neo-positivist paradigm in geography.

\section{References}

D'Haenes L. \& Proulx S., 2000. The changing stance of the Canadian Government in an age of globalization and information. Gazette, 62(3-4): 281-299. Sage Publications, London, Thousand Oaks \& New Delhi (http:// gaz.sagepub.com/content/62/3-4/281.short), DOI: $10.1177 / 0016549200062003007$.

DiCKENSON J., 1993. Who speaks for geography? Retrospect on an International Congress of Geographers. Area, 25(3): 283-285.

DomańsKi R., 1998. Zasady geografii społeczno-ekonomicznej (Principles of socio-economic geography). Wydawnictwo Naukowe PWN, Warszawa.

Friedmann J., 1966. Regional development policy: A case study of Venezuela. MIT Press, Cambridge, MA, London.

Goban-Klas T., 2006. Media i komunikowanie masowe (Media and mass communication). Wydawnictwo Naukowe PWN, Warszawa.

НоғмокL T., 1997. Stymulacyjna rola sieci teleinformatycznych w dziedzinie transferu technologii i pobudzania innowacyjności w Polsce (Stimulating role of computer networks in technology transfers and stimulation of innovations). In: Markowski T., Stawasz E. \& Zembaczyński R. (eds), Instrumenty transferu technologii i pobudzania innowacji. Wybór ekspertyz. Zespół Zadaniowy ds. Polityki Strukturalnej w Polsce, Warszawa.

ITU (International Telecommunication Union), 2006. World Summit on Information Society Golden Book. Geneva. 
ITU (International Telecommunication Union), 2011. World Summit on Information Society. Geneva.

KuHN T., 1963. The structure of scientific revolutions. University of Chicago Press, Chicago.

LEVINSON P., 1997. The soft edge: A natural history and future of the information revolution. Routledge, New York.

Longley P.A., Goodchild M.F., Maguire D.J. \& Rhind D.W., 2001. Geographic Information Systems and Science. John Wiley, Chichester, Sussex.

OECD 2001. Glossary of statistical terms. Available at: http:// stats.oecd.org/glossary/index.htm.
Peterson M.P., 2007. Mapy i Internet: pogłębianie się kontrastów w rozwoju (Maps and the Internet: deepening of development contrasts). Polski Przeglad Kartograficzny, 39(4): 333-339.

SteINITZ C., 1993. GIS: A personal historical perspective. GIS Europe, 2, June.

Understanding the digital divide, 2001. OECD. Available at: http://www.oecd.org.

WARNECKE H.J., 1993. The fractal company: A revolution in corporate culture. Springer-Verlag, Berlin and New York. 